\title{
Zeichnungsschein/Subscription Form
}

Der Zeichnungsschein/Subscription Form weist neben dem Namen des Begünstigten die konkrete Anzahl seiner ihm zugeteilten virtuellen Anteile aus. Ferner enthält die Subscription Form das Einverständnis des Mitarbeiters mit den Bestimmungen des VSOP und bildet in rechtlicher Sicht den verbindlichen Vertragsschluss zwischen ihm und der Gesellschaft durch die verbindliche Annahme ( $\$ 151$ BGB) des Angebots (§ 145 BGB) des Unternehmens.

\section{Musterformulierung}

Hiermit zeichne ich die o. g. virtuellen Geschäftsanteile zu den im Einzelnen im Beteiligungsplan „Virtueller Beteiligungsplan (Virtual Stock Option Plan) für Mitarbeiter und Führungskräfte“ festgelegten Bedingungen.

\section{Musterformulierung}

Das Angebot an den Begünstigten erfolgt im Rahmen eines Zeichnungsscheins, der diesem Beteiligungsplan als Anlage beigefügt ist. Der Begünstigte nimmt das Angebot der Gesellschaft mit Unterzeichnung des Zeichnungsscheins und dessen Rückgabe an die Gesellschaft an. 